\title{
NATURALIZACIÓN DE LA ESPIRITUALIDAD (2)
}

\author{
JORDI FONT \\ Fundación Vidal i Barraquer \\ Universitat Ramon Llull, Barcelona
}

\begin{abstract}
RESUMEN. Partiendo de la afirmación de que la dimensión espiritual es constitutiva del ser humano, presentamos la propuesta teórica de un modelo antropológico que da cuenta de la espiritualidad como emergencia de la vida y sustrato para la vivencia de una fe religiosa conscientemente asumida. La espiritualidad es, según el autor, una emergencia de la vida, junto a la salud. La visión psicoanalítica resulta adecuada para estudiar el proceso de evolución madurativa humana y posibilita el acceso al mundo inconsciente utilizando, en este caso, la Teorías de las Relaciones Objetuales (TRO). Cuál sea el punto de partida de la realidad psíquica se aborda a partir del punto 0 de Bion. Se observa también la concomitancia de la evolución madurativa humana con la maduración espiritual, señalando la importancia de la función simbolizadora, así como las distintas fases de maduración espiritual y su correlato psicoanalítico. ¿Puede nuestra mente, nuestro cerebro percibir el misterio inefable? Abordamos el proceso espiritual con toda la complejidad del crecimiento espiritual hacia la experiencia mística. ¿Cómo se produce psicológicamente el fenómeno místico? ¿Qué relación hay entre la experiencia inefable y las 'neuronas'? Para dar cuenta de estas realidades y contestar estas preguntas se precisa un ámbito teórico no reducible al de la ciencia natural.
\end{abstract}

PALABRAS CLAVE: emergencia de la vida, espiritualidad, inconsciente, psicoanálisis, mística.

\section{The naturalization of spirituality (2)}

ABSTRACT. Starting from the affirmation that the spiritual dimension is constitutive of the human being, we present a theoretical proposal of an anthropological model that accounts for spirituality as an emergency of life and substrate for the living of a consciously assumed religious faith. The psychoanalytic view is adequated to study the evolution process of human maturation and makes possible the access to the unconscious world, in this case, the Object Relations Theory (ORT) is used as theoretical model of interpretation. What it may be the starting point of psychic reality is addressed point 0 of Bion. The concomitance of human maturation with spiritual maturation is also observed, pointing out the importance of the symbolizing function, as well as the different phases of spiritual maturation and its psychoanalytic correlate. Can our mind, our brain, perceive the ineffable mystery? We will approach the spiritual process with all its complexity of spiritual growth towards the mystical experience. How is the mystical phenomenon produced psychologically? What is the relationship between ineffable experience and 'neurons'? To give an account of these realities and to answer these questions, a theoretical field not reducible to that of natural science is necessary.

KEY WORDS: spirituality, emergency of life, unconscious, psychoanalysis, mysticism.

\section{INTRODUCCIÓN ${ }^{1}$}

En esta ponencia, nos proponemos presentar, un breve estado de la cuestión que servirá como marco para situar la propuesta teórica de un modelo antropológico que da cuenta de la espiritualidad como una emergencia de la vida y que es sustrato para la vivencia de una fe religiosa conscientemente asumida. En su

1 Este artículo, con entidad propia, puede leerse como una parte segunda del también publicado en este número: CAÑón, C. «Naturalización de la espiritualidad (1)». 
desarrollo queda manifiesto la insuficiencia de la metodología de las ciencias de la Naturaleza para dar cuenta de la realidad humana de la espiritualidad.

\section{EsTADO DE LA CUESTIÓN}

\section{La espiritualidad como emergencia de la vida. Conceptos previos}

Creo que es fundamental precisar desde el inicio los límites del significado que atribuimos al concepto de experiencia religiosa y de experiencia espiritual. Entendemos lo religioso como todas aquellas mediaciones empíricas y simbólicas, formalizaciones y objetivaciones, que pueden ser compartidas (textos, espacios, ritos, liturgias...) y que vehiculan la relación del sujeto y del grupo con la realidad trascendente.

Espiritualidad es la tendencia humana hacia una realidad no física vivida como algo que emerge de uno mismo pero que no puede manejar conscientemente, pero si aportar mediaciones empíricas y simbólicas que la faciliten. La diferencia entre espiritualidad y religión estaría entre el dedo que señala (sería la religión), y el lugar hacia dónde señala (sería lo espiritual inefable).

La palabra que puede definir de forma más clara la percepción de espiritualidad es la palabra intuición. Intuimos que hay un misterio que captamos, que no se acaba, la búsqueda de algo más. Es una vivencia. Una vivencia sin símbolos es vivir la misma vida, captar lo que estoy viviendo

\section{Dos emergencias de la vida: la espiritualidad y la salud}

La naturaleza es lo que palpamos y lo que se esconde en agujeros que no sabemos detectar. Nunca se agota, siempre va más allá (no agotan lo que es la vida, lo que supone la búsqueda de la indeterminación humana que busca al otro, pero que no se acaba, la búsqueda de algo más).

La vida es lo que conocemos por experiencia propia y por experiencia del cosmos que va evolucionando. Y esta vida se manifiesta en dos emergencias que son concomitantes: la emergencia que llamamos salud es la expresión de la fuerza vital que mantiene el bien-ser (puede objetivarse con indicadores ${ }^{2} \mathrm{ob}$ jetivos) y la emergencia de la vida que es la espiritualidad que intuye, pero sin comprender en su plenitud.

2 La definición de la salud mental y sus indicadores fueron establecidos en el congreso de Perpiñán por un grupo de investigación interdisciplinario de profesionales: médicos, biólogos, sociólogos, psiquiatras psicólogos, políticos... Después de un largo proceso de estudio y de reflexión, se elaboró una definición de salud y de salud mental, basándose en la experiencia referida a nuestra cultura, a nuestro tiempo y a la ideología de fondo que, a pesar de la diversidad de los participantes, era suficientemente representativa: Go, L.J.-FONT, J. «Definició de salut»; DD.AA., Funció social de la medicina, X Congrés de Metges i Biòlegs de Llengua Catalana (Pepinya), Barcelona, Academia de Ciencies Mediques de Caralunya i Balears. Societat Catalana de Biologia, 1976. 
La espiritualidad, emergencia de la vida, es la potencia vital que avanza asintóticamente y se desarrolla en un proceso evolutivo de maduración. La evolución va desde un estado de relación egocéntrico, de supervivencia, que ofrece seguridad, a un estado de relación con la alteridad que supone pasar de lo conocido a lo desconocido, que es el otro, pasando por el riesgo de abandonar las seguridades, hasta poder alcanzar una unión mística no dual. En este sentido, espiritualidad es una experiencia subjetiva referida a un proceso de maduración que, a partir de la experiencia de la incompleción humana, puede alanzar los niveles de experiencia mística inefable. Podemos decir que espiritualidad es la experiencia del sujeto que se dispone a entrar en relación interior con algo que es una realidad que le atrae con una cualidad superior a las seguridades de supervivencia que le aseguran bienestar.

Nos acercamos a la espiritualidad, desde un modelo antropológico con el que dar cuenta de las dos emergencias de la vida a las que nos hemos referido, la espiritualidad y la salud. El objetivo de aplicar este modelo es que nos permite comprender el proceso evolutivo madurativo de la vida humana. Y al buscar la comprensión, y no meramente una explicación que establezca relaciones causales. Con ello apuntamos a un marco de discurso no reducible a la ciencia natural empírica, aunque integre resultados actuales de las ciencias neurológicas. Este marco del discurso lo entendemos compatible con las visiones que consideran insuficiente el naturalismo clásico, de las que hemos hablado en la introducción.

En síntesis, desde el punto de vista antropológico, la vida espiritual es un proceso vital, psicobiológico evolutivo, hacia la maduración de la persona humana en el que distinguimos:

El proceso evolutivo madurativo, de la vida humana, en el que la espiritualidad es una emergencia de la vida cuya maduración no acaba, trasciende el ciclo vital. Es una dimensión que no se agota con el ciclo vital, hay una dimensión que lo trasciende y tiende hacia una relación de unidad total, en una vivencia no-dual.

Además, la maduración espiritual se manifiesta psicológicamente pero no la podemos poseer. Solo se percibe, es inefable pero incorporada a nosotros, vivimos en Ella, (podría expresarse en palabras de Pablo: «No soy yo quien vive, es Cristo que vive en mí», Ga. 2,20).

Hay que admitir que hay realidades no físicas que podemos intuirlas. Queda abierta la posibilidad de intuir otra Realidad, la de Dios.

Mundo inConsCiENTE. MODELo PSicoANALítico RELACIONES PERSONALES (OBJETALES)

El modelo psicoanalítico. Teoría de las relaciones personales (objetuales - TRO)

Nos queda abierto el interrogante de si es posible saber qué ocurre cuando el ser humano experimenta una realidad que va más allá, que trasciende la 
realidad inmanente, cuando experimenta algo absoluto, una realidad última, una plenitud. Queda el interrogante de saber qué es aquello que se vive al decir Dios, al experimentar algo irreducible e inabarcable, pero cercano e íntimo. Para responder a esas cuestiones vamos exponer que la mente humana, (y sus relaciones personales), se produce y expresa principalmente sobre la base de la vida inconsciente. Y que para comprender cómo se procesan en nuestra mente sus actividades y abordar el cómo mentalmente podemos decir «Dios» nos servimos del método psicoanalítico de la «Teoría de las relaciones objetuales» (T.R.O).

La espiritualidad se vive psicológicamente en el mudo inconsciente y la vida inconsciente es objeto principal de estudio del psicoanálisis. Se comprende por qué relacionamos espiritualidad y psicoanálisis, por qué escogemos el modelo psicoanalítico para comprender la vida espiritual. Hay aportaciones contemporáneas muy reveladoras que confirman algunas tesis apuntadas por Freud y corroboradas por la neurociencia.

Fue Sigmund Freud el que al poner al descubierto el mundo de nuestro inconsciente $^{3}$ inicia el camino que ha seguido evolucionando hasta hoy. Melanie Klein, D. W. Winnicott, W. R. Bion, Ogden... Otras Escuelas Americanas y Europeas, además de nuevas tendencias actuales como el psicoanálisis evolutivo y el psicoanálisis relacional. Nuestra propuesta se construye sobre la Teoría de las relaciones objetuales (T.R.O.), teoría psicoanalítica de las relaciones interpersonales e intrapersonales,

El mundo inconsciente es básico para comprender la espiritualidad, como también para entender la salud. La espiritualidad, como tendencia hacia la unión con una realidad que le trasciende, se experimenta sobretodo en el mundo inconsciente que tiene su base neurológica. Con la incorporación de los resultados actuales de la neurociencia, se confirman algunas aportaciones psicoanalíticas y se proporciona el ámbito teórico adecuado con el que construir el modelo que permita comprender esta emergencia de la vida, que es la espiritualidad.

$\mathrm{Al}$ desvelar la realidad del mundo interior, el psicoanálisis posibilita el acceso a la psicología del inconsciente y es en el inconsciente, donde se vive básicamente la vida espiritual. Pensemos por ejemplo, en la conocida «discreción de espíritus» [313-336] «buen espíritu y mal espíritu» [32] de los ejercicios Ignacianos y en todo el método de los Ejercicios Espirituales de Ignacio de Loyola que constituyen un verdadero tratado del mundo inconsciente espiritual dirigido a liberar la persona de «su propio amor, querer e interés» [189] en su búsqueda y entrega al amor a Dios y al prójimo, amor que «se pone más en

3 Son bien conocidas las críticas a la religión en la obra de Freud, especialmente en Totem y tabú (1913), El malestar de la cultura (1927), El futuro de una ilusión (1928) o Moisés y el monoteísmo (1938) entre otros. Es menos conocida sin embargo la correspondencia con un amigo, el pastor protestante Oscar Pfister, o la existencia de una nota sobre qué es la mística de 1939 encontrada sobre su escritorio después de su muerte. 
las obras que en las palabras» como se lee en la «Contemplación para alcanzar amor» [230-237 final del libro y síntesis espiritual del amor místico ${ }^{4}$.

El modelo psicoanalítico permite una aproximación antropológica al proceso evolutivo madurativo de la vida psicobiológica que tiene carácter inconsciente. $\mathrm{Y}$ es precisamente esta vida psicobiológica la que proporciona la base corporal para poder manifestar el proceso evolutivo madurativo al que nos referimos como espiritualidad. Pero mientras que para la salud hay indicadores objetivos corporales y subjetivos psicológicos, para la espiritualidad sólo pueden darse señales indicadoras objetivas de maduración o de regresión espiritual, a modo de niveles de evolución y maduración espiritual que escapan a la objetivación y que, para el mismo sujeto que las vive, son inefables.

\section{Relaciones personales (objetuales). ¿Cómo podemos decir «Dios»?}

Toda experiencia humana se origina en una relación, también la experiencia religiosa es relacional. Debemos declarar cómo entendemos las relaciones personales desde la psicología analítica. A las relaciones personales también las denominamos relaciones objetuales, relaciones de objeto mental.

Denominamos objeto mental a la relación que se establece entre uno mismo y el término de una relación. Esta relación viene promovida por las pulsiones y el objeto se constituye como destino de las pulsiones. Denominamos pulsiones a las fuerzas que nos mueven desde dentro y nos impulsan a hacer alguna cosa o a no hacerla, a sentir, a pensar, a recordar determinadas cosas y a olvidar otras. Freud las denomino Trieb (del alemán) que se tradujo como instinto. Freud mismo evolucionó al ir interesándose en la actividad del Yo. Melanie Klein, luego Fairbairn, que rebajó la importancia de los instintos y luego la Psicología del Yo, describe aspectos distintos de lo instintivo.

Los objetos mentales son las personas o cosas, todo ente animado, inanimado o abstracto, o parte de ellos, (objetos parciales) hacia los cuales se dirigen nuestra pulsiones o motivaciones fundamentales, los deseos. Podemos denominar estas relaciones de objeto como relaciones personales o relaciones humanas. La vida psíquica se constituye en la búsqueda y la constitución de una relación.

Debemos distinguir entre objetos externos y objetos internos. Los objetos externos percibidos tal como entran en relación con nosotros son interesantes para explicar parcialmente las representaciones mentales y las conductas, pero su acción está siempre mediatizada por el procesamiento que se hace en el mundo interior del sujeto.

El objeto interno es el sedimento de vivencias y representaciones mentales que se producen en el conjunto de relaciones con un objeto externo (las ansiedades, los sentimientos, las ideas, los recuerdos, etc.). Los objetos internos solo coinciden en parte con los externos. El objeto interno se forma a partir de la

4 Loyola, I., Ejercicios Espirituales, Editorial Sal Terrae, Santander, 2010 
incorporación de los objetos externos que han sido interiorizados y metabolizados, pero se forma también a partir de la persona que lo posee ${ }^{5}$. El objeto interno es siempre activo, dinámico, si bien de manera inconsciente. La persona misma es capaz de generar objetos internos a partir de una parte del propio yo. Esto quiere decir que los objetos internos son fruto en parte de la propia producción (pulsión, deseo) y en parte de la incorporación del mundo exterior.

Uno de estos objetos mentales constituidos en el interior de nuestra mente puede ser Dios. Hay objetos externos que nos hablan de Dios: las palabras, la tradición, toda la actividad simbólica y ritual, etc.; por otra parte, en el propio yo (el «self» ${ }^{6}$, el sí mismo) se produce un objeto interno mental. El objeto mental interno Dios es en parte fruto de la proyección del propio yo, que se incorpora a un objeto externo (una palabra, una tradición, una educación...) y se convierte en un objeto interno propio, el objeto mental interno Dios.

¿Qué supone esto? Supone que la configuración del objeto mental interno Dios en parte nace del «Yo» y en parte de la incorporación de la relación con el mundo exterior — con objetos externos-que habla de Dios.

Alguien puede pensar que esto supone un reduccionismo psicológico y que hacemos depender la experiencia religiosa del dinamismo psíquico. Debemos aclarar que hablar desde el punto de vista psicológico no excluye ni tampoco muestra la existencia de otra realidad que está más allá del mundo físico. Lo que intentamos mostrar es que la experiencia de Dios como, de hecho, toda experiencia humana, está vehiculada por la persona humana, que es mente y cuerpo. La persona puede mostrarse sensible ante realidades externas que, juntamente con las internas, configuran una experiencia espiritual. Nosotros analizamos cómo se produce esta experiencia, no qué es lo que la produce, ni quién ni por qué.

\section{Proceso de evolución madurativa humana. Visión psicoanalítica de la evolución}

Desde el origen, el ser humano establece relaciones internas y externas consigo mismo. Ya en la vida fetal, antes de salir de la matriz materna, el bebé es tributario de experiencias relacionales.

El bebé es capaz de inaugurar una cadena ininterrumpida de experiencias que lo llevaran a abrirse paulatinamente a niveles cada vez más evolucionados, con la posibilidad de ir siendo consciente y de progresar desde las primitivas

5 Ogden, T. H., La matriz de la mente. Las relaciones de objeto y el diálogo psicoanalítico, Tecnipublicaciones, Madrid, 1989.

6 El concepto psicoanalítico del self comienza explícitamente con Hartmann (7) cuando hace la distinción entre el yo — como sistema psíquico-y el self — como concepto referido al «uno mismo». Para Hartmann el «yo» no es sinónimo de «personalidad» ni de «individuo»; no coincide con «sujeto» como opuesto al «objeto». La palabra «self» indica las formas en que el individuo reacciona ante, sí mismo, en que se percibe, piensa y valora a sí mismo y cómo, mediante diversas acciones y actitudes, trata de estimularse o defenderse. El self es, por lo tanto, un concepto intermedio entre los relacionados con los fenómenos intrapsíquicos y los concernientes a la experiencia interpersonal. 
experiencias sensoriales, emocionales y cognitivas, hasta la consecución de procesos más complejos en que se integran las percepciones y la formación de conceptos.

Esta concepción de la realidad psíquica desde el comienzo de la vida fue estudiada por Melanie Klein ${ }^{7}$. Posteriormente ha sido profundizada y completada ampliamente ${ }^{8}$.

Para comprender el proceso madurativo personal lo exponemos según el modelo psicoanalítico de las Relaciones Objetuales (TRO):

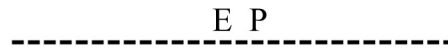

E P M D

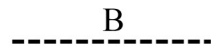

T P

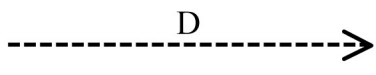

H O F Hp....

Señalamos los momentos o «fases» evolutivas de la maduración.

En la figura, la línea es el proceso evolutivo. En la parte superior EP (Esquizo-Paranoide) y D (Depresiva) son las fases (o «posiciones») del modelo psicoanalítico.

En la parte inferior está la nosología psiquiátrica (Esquizoide, Paranoide, Maníaca, Depresiva), (Trastornos de Personalidad). (Histeria, Obsesión, Fobia. Hipocondría...).

En el momento dramático del nacimiento, cuando el caos de información que llega a la corteza cerebral aún no ha podido ser organizado suficientemente, el niño ensaya tentativas impulsado por sus necesidades más básicas: respirar, alimentarse — con el alimento biológico y afectivo-, contactar sensorialmente, etc. Las primeras relaciones son confusas, aún no diferenciadas: no percibe aún quién es él y quién es el otro está aún faltado de identidad?.

Se vive una situación de abandono súbito e inesperado, sumido en un caos vital de confusión. Se ahoga el centro respiratorio del infante acusa carencia de oxígeno y activa la alarma y la respuesta de los pulmones que se despliegan.

Ante la aparición de miedos, temores y terrores, se defiende (estos procesos ocurren de manera inconsciente) escindiendo la realidad interna caótica y temida, en partes buenas y partes malas a lo que llamamos posición EsquizoParanoide $(\underline{E} \underline{\mathrm{P}})$. Son experiencias que quedan inscritas y que pueden ser revividas emocionalmente llegados ya a la fase adulta, aunque con contenidos nuevos.

La relación con los aspectos de la realidad percibida de manera escindida entre parte buena y parte mala, produce una relación parcial en tanto que escindida, y, por lo tanto, pierde el conjunto entero, la realidad total. «Relación parcial de objeto» en lugar de relación total. La tendencia que surge defensivamente

7 KLEIN, M.: «Principios psicológicos del análisis infantil» (ed. Original: 1926), en: Obras completas, Tomo II. Buenos Aires, Paidós, 1975.

8 Bion, W. R., Volviendo a pensar, Hormé, Buenos Aires, 1985 (3ª edición).

9 Segal, H., Introducción a la obra de Melanie Klein, Paidós, Buenos Aires, 1975. 
es identificarse con la parte buena e idealizarla, escapándose de la parte mala, peligrosa. (El «objeto» bueno idealizado). Y también puede tender a la identificación con la parte mala y sumirse en un auténtico infierno del cual se podrá librar gracias al soporte afectivo recibido de los cuidadores. Son movimientos dramáticos que nos pueden sugerir relación con los movimientos religiosos, espirituales del adulto.

Al progresar la evolución de esos conflictos se llega a alcanzar una comunicación del niño con la realidad no ya de una manera escindida y parcial, sino aceptándola toda entera, (Posición Depresiva D). Es el paso del principio del «placer» al principio de «realidad». A este estado de maduración se llega pasando antes por el proceso primario, que es el modo de funcionamiento mental. En él predomina el principio de placer: buscar sólo el placer, lo que gusta, y sin dilación: «todo y enseguida». Se llega al proceso secundario, en el que el individuo admite la adecuación a la realidad, en el que se rige por el principio de realidad, que corrige y modifica el principio de placer para establecer una relación con la realidad del mundo externo. Todo este proceso se va repitiendo después durante la vida y nutre la estructura mental que da el estilo de la personalidad de cada individuo. Ya se pueden observar las semejanzas que esta evolución psicológica madurativa tiene con el proceso evolutivo religioso.

Nos podemos preguntar, ¿cómo se realiza este paso tan fundamental en la evolución de la persona infantil y la del adulto?

Lo que sucede es que el niño ha comenzado a poder aceptar las frustraciones «tolerancia a las frustraciones» (pérdidas, carencias, muertes parciales) como un paso hacia obtener una relación total con la realidad que le resulta más satisfactoria que no los placeres y gustos de menos valor que obtenía con las relaciones parciales. Por ejemplo, una sonrisa de la madre cuando él renuncia al placer de obtener enseguida el alimento que exigía llorando le permite crecer en su capacidad emocional y cognitiva y establecer relaciones de creatividad mental y relacional. Es lo que se llama función psicológica de la simbolización.

La elaboración del duelo pasa por aceptar y renunciar a objetos que le producen placer a favor de los objetos nuevos que tienen un valor simbólico gratificante. Con esta función de tolerancia, el niño comienza a gozar de los valores simbólicos (la sonrisa de la madre, etc.). La función simbólica es la que está presente en el proceso que llamamos proceso de duelo.

Siguiendo su maduración el niño puede llegar a tener experiencias espirituales simbólicas, en el desarrollo de las cuales y después de largos períodos madurativos se podría llegar a una base psicológica capaz de abrirse a la experiencia mística en la medida en la que haya aceptado y optado por seguir el camino de la trascendencia, específica de los seres humanos, que posibilitan abrirse a realidades no solo simbólicas sino a la realidad última, inefable pero que ha sido posible intuir y seguirla. Es la experiencia del Misterio, de aquello desconocido pero percibido. Maduración que puede llegar a culminar en el nivel místico. 


\section{El punto 0 de Bion}

Son muy sugerentes las aportaciones del psicoanalista de origen indio Wilfred Bion ${ }^{10}$, que siguiendo el modelo de las relaciones personales o de relaciones de objeto, expone una metapsicología que abarca la comprensión de las experiencias humanas que se producen en la búsqueda de la trascendencia. Aporta algunas propuestas elaboradas a partir de su experiencia clínica psicoanalítica. De entre la gran cantidad de ideas originales que ha aportado me gustaría recoger algunas referidas a la trascendencia.

Para Bion, el punto de partida de la realidad psíquica es lo que él denomina «Punto 0 », que es un hecho original: es la cosa en sí misma, lo desconocido, la verdad absoluta, la realidad última incognoscible. Esta realidad se manifiesta a través de las transformaciones que va haciendo la persona durante su vida y que la afectan no solamente en el conocer sino también en el ser.

Los primeros elementos de la vida mental son inconscientes y alucinatorios, y están vinculados a la sensación de catástrofe. La sensación flotante de catástrofe constituye la condición fundamental de nuestra existencia y tiene contenidos específicos, como son el temor al nacimiento, el temor a la muerte, al cambio, a lo ilimitado, a la propia ipseidad, etcétera. Esta sensación de catástrofe puede estar alimentada por la diferenciación entre uno mismo y la nada, que es una distancia infinita y que la padece todo el mundo, si bien algunos no la experimentan. Bion se pregunta si es esa distancia la causa que produce sensación de catástrofe.

La función de la vida psíquica consiste en transformar las sensaciones catastróficas en acontecimientos psíquicamente aceptables. Por ejemplo, los mitos de la creación y de destrucción expresan esta transformación. Se pasa de lo inconsciente al pensamiento consciente a través de los mitos, como también a través del trabajo onírico y de la reflexión sobre los símbolos. La sensación de catástrofe es un principio constitutivo primordial, como lo es el agua o la atmósfera, y sirve de vínculo entre diversos aspectos de la personalidad.

¿Cómo se reacciona delante de la catástrofe? La verdadera respuesta primordial y desarrollada a la catástrofe es la fe. Ahora bien, no entendemos la fe en un sentido religioso estricto, aunque no la excluye, sino como confianza básica. La inconsciencia de la fe sale al encuentro de la inconsciencia de la catástrofe.

La fe es una receptividad pura, una espera atenta. Esta postura es incómoda: tolera la fragmentación, el vacío caótico, las tempestades psíquicas... En la fe se da una suspensión de la mente. Hace falta que haya una atención libre y flotante, una cierta inconsciencia, un vaciamiento de sí mismo, para llegar a alcanzar la receptividad de la fe.

El punto 0, la realidad emocional esencial, como tal, es incognoscible, pero no aleja de la fe de manera que no pueda ser encontrada. La fe en búsqueda es

10 Eigen, M., «En torno al punto de partida de Bion: De la catástrofe a la fe» en: Clínica e Investigación Relacional, 8, 2014, pp. 125-143 
lo que lleva a la situación mística, no solamente religiosa. Entonces, la transformación que se produce es en el plano del ser y no solamente del conocer.

Entre catástrofe y fe hay una intención continua durante toda la vida. Se puede interferir este ritmo de interacción entre fe y catástrofe por falta de paciencia o de tolerancia a la hora de vivir en la posición de catástrofe o de intentar aferrarse a la posición de búsqueda de la fe más tiempo del que conviene. En cambio, si se persiste y se mantiene en este período de gestación, quizás se llega. Es aquí donde Bion ve un paralelismo entre este proceso y la noche oscura de los sentidos en los místicos.

¿Cuál es el futuro de estas experiencias iniciales en la vida adulta? Con el transcurso del tiempo se puede perder sensibilidad por la catástrofe; entonces es la fe la que puede rescatar la catástrofe. Si la fe no lo hace, se tiene a debilidad la consciencia de catástrofe, lo cual comporta perder sensibilidad hacia nosotros mismos. Esto ocurre cuando nos orientamos hacia objetos externos y hacia tareas de supervivencia, cuando hacemos más caso de las situaciones externas para eludir las internas. La fe, o confianza básica, es una tendencia maduradora original. Es una entidad que aparece, así como también la catástrofe, cuando se nos ha despojado de todo. Es la capacidad liberadora por excelencia. Es nuestra herencia y nuestro destino más profundo. La fe es la no mentida.

EL PROCESO EVOLUTIVO MADURATIVO DE LA VIDA ESPIRITUAL, DESDE LA VISIÓN PSICOANALÍTICA

Ya hemos tratado de la evolución madurativa humana. Veamos la concomitancia con la maduración espiritual.

En las fases más primerizas de maduración, la persona «creyente» sitúa su experiencia ante la realidad de Dios evolucionando, desde la posición Esquizo Paranoide (un Dios mágico) con incertidumbres. Si sigue buscando (posición $\mathrm{D}$, depresiva) y entra en una relación de entrega al otro, y al Dios de Bondad, puede llegar a sentir que no es él mismo quien produce este cambio sino que le es dado por el mismo Dios. Se da el paso hacia la posición depresiva (posición D). Aun en ella puede haber momentos de turbulencias de fase primeriza (posición EP). Las dos posiciones EP «D son reversibles. Se puede pasar de una experiencia espiritual sana a momentos de confusión, son posibles en la misma persona, si bien en la unión mística cumbre ( $7^{\mathrm{a}}$ Morada: «todo queda vivido en una sola vivencia»).

\section{Importancia de la función simbólica}

La simbolización es el proceso en que el sujeto, al renunciar a las pulsiones instintivas de placer, alcanza otra realidad nueva más valorada, el objeto simbólico. Los símbolos aparecen en la llamada posición depresiva y exigen una inhibición de pulsiones instintivas dirigidas hacia el objeto. Freud habló de 
sublimación, noción que no acabó de desarrollar. Sin embargo, es más correcto hablar de simbolización. La simbolización ofrece capacidad creativa para alcanzar y trascender los objetos originales. El símbolo no es el equivalente al objeto perdido, sino que es un objeto nuevo, y lo representa sin perder las características de aquél

La génesis de la formación de los símbolos reside en el hecho de que se reconoce, en parte, las pulsiones instintivas y se desplazan hacia un objeto del cual espera una satisfacción mayor ${ }^{11}$. La renuncia conseguida de los fines instintivos solo se produce mediante un proceso de duelo, de pérdida y de recuperación interna de aquello a lo que se ha renunciado.

La noción de símbolo psicológico y su realidad dan una base para comprender cómo se puede dar la experiencia de trascendencia, la experiencia de inmanencia-trascendencia: se parte de una realidad (inmanente) y se busca ir hacia otra realidad (es decir, trascender la primera).

\section{Fases de maduración espiritual y su correlato psicoanalítico}

En el proceso de maduración espiritual, aunque se trata de un continuum en su evolución, pueden diferenciarse varias fases que encuentran su paralelismo con las fases de evolución espiritual.

Nuestra propuesta señala la concomitancia que se puede observar entre las etapas: posición esquizo-paranoide y posición depresiva, con las etapas de evolución espiritual. Esta concomitancia es plausible dado que toda experiencia humana es percibida por sus «objetos mentales», también los de Dios, espíritu, bondad..., y todos ellos son vehiculados por la misma función psicológica consciente e inconsciente.

\section{1) Fase: "purgativa», posición esquizo-paranoide}

Lo específico de esta fase, lo que se vive psicológica y espiritualmente sin los miedos, ante el caso confusivo y frente a ello, es la reacción defensiva que busca separar escindir el peligro, la realidad amenazadora y hostil identificándose con una parte que resulta tolerable y rechazando o negando la otra parte. Así ocurre que se pierde el contacto con la realidad total, objetos mentales parciales, no totales.

Psicoanalíticamente: en la posición esquizo-paranoide hay ansiedades y terrores ante lo negativo de las relaciones primerizas, hay escisiones que originan relaciones parciales de objeto, el objeto es todo bueno o todo malo. El objeto mental interno (Dios) puede ser vivido como objeto malo, amenazador, incluso originando ansiedades persecutorias, originando culpabilidades, castigos expiatorios. O convertirse en lo malo (demonio), que se identifica posesivamente,

11 SEgal, H., op. cit. 
(posesión diabólica). Pueden darse con identificaciones delirantes (con lo sagrado, Dios, o con el diablo).

Espiritualmente: Se busca poder superar y liberarse de deseos malos, perversos, que mantienen sometidos a pensamientos y conductas egoístas, las cuales si bien placen, no son queridas, son tentaciones que mueven a apartarse del amor a Dios y a los demás. Son difíciles de superar porque atraen con fuerza. Se teme a Dios como juez exigente que condena, con temores de ser rechazado, y abandonado si no repara o expía sus culpas. Predominan egocentrismos que impiden progresar en el amor a la alteridad, a Dios y al prójimo.

\section{2) Fase iluminativa, tránsito a la posición depresiva}

Lo específico es el tránsito hacia una relación personal en la que se percibe la realidad del otro integrando lo frustrante con lo bueno y se desplaza el buscar el bienestar egocéntrico hacia el buscar el bien del otro

Espiritualmente: Se es consciente del egoísmo pecaminoso que aparta del amor a los demás y se busca descubrir los engaños que encubren los egoísmos con falsas motivaciones y apariencias. El deseo básico es entrar en conocimiento de la realidad amorosa de Dios y el prójimo para amar cada vez más, en un proceso de crecimiento madurativo. Así se van alcanzando actitudes capaces de discernir lo que es bueno o lo que es malo, para sí y para los otros, avanzando en el amor a la alteridad.

Psicoanalíticamente: En la posición depresiva se alcanza una relación de objeto total, concienciando lo que son mecanismos de defensa que dan seguridad engañosa, descubriendo mecanismos defensivos encubridores de conflictos, que calman ansiedades en lugar de aceptarlas, contenerlas, elaborarlas. La posición depresiva se corresponde con la capacidad de elaborar duelos, de resolver los conflictos, las frustraciones y las pérdidas, de desarrollar capacidades creativas, de pasar del egocentrismo biológico a la relación de amor a la alteridad. La función simbólica abre a la creatividad y novedad.

\section{3) Fase unitiva, maduración, asintótica..., dentro la posición depresiva}

Espiritualmente: La vía unitiva muestra progreso en la capacidad de desarrollo espiritual, en la relación de amor hasta unirse, sin confundirse, con el amado. El núcleo esencial es la dimensión de amor unitivo, de la entrega total, de la identificación con el objeto amado, hasta la fusión —no confusión- con el objeto. Unidad no dual, experiencia del misterio.

Psicoanalíticamente: En la vía unitiva el proceso evolutivo psicológico estaría en la dimensión de la posición depresiva, en una asintótica experiencia de relación unitiva. Entramos en una dimensión que, si bien tiene su base biopsicológica en la mente, en el cerebro, escapa a la comprensión del lenguaje simbólico. Es una realidad que no se puede expresar con nuestras dimensiones de espacio y tiempo, trasciende a ellas, pero existe la capacidad de intuir una realidad que, no siendo de orden material, no solo se vivencia que «existe» sino 
que «es». El lenguaje místico lo expresa como vivencia del misterio de amor, intentando solamente comunicar la vivencia percibida.

Se ha propuesto también lo que, psicoanalíticamente, se denominaría la «posición contemplativa» (Matte Blanco).

\section{Proceso ESPIRITUAL DE CRECIMIENTO ESPIRITUALHACIA LA EXPERIENCIA MÍSTICA}

Hemos llegado al núcleo de nuestra propuesta. Nuestra mente, nuestro cerebro, ¿puede percibir el misterio inefable? ¿Hay vivencia de amor unitivo, místico?

Nuestro punto de origen ha sido: la espiritualidad es una emergencia de la vida humana. La salud humana es también una emergencia de la vida. La salud humana es una dimensión que se ex-tiende hasta el fin de su ciclo vital.

La espiritualidad es una dimensión que trasciende la finalidad de la vida humana, tiende y apunta a una realidad que escapa al orden físico, cósmico. La espiritualidad aspira a una realidad que intuye pero que no puede ser poseída. La finalidad, una vivencia unitiva de amor, distingue la espiritualidad de la salud.

Espiritualidad y salud, ambas siguen un proceso evolutivo de crecimiento, asintótico. Pero hay un salto epistemológico cuando pasamos a considerar la intuición de una realidad que no es de orden físico.

Nuestro intento es mostrar desde la visión antropológica cómo puede ser vivida la experiencia mística. No tratamos del porqué se produce esa experiencia ni lo que ella es en sí, aunque pueda ser percibida.

Descripción de lo que entendemos por experiencia mística.

La mística es un proceso en parte activo y en parte receptivo (o pasivo), es una activa pasividad, una receptividad amorosa que se origina insensiblemente por un progresivo despojamiento de los propios intereses para ir en busca de los del otro. Hay un deseo amoroso del otro que lleva a la renuncia de los deseos personales, ya sean deseos sensibles, sensoperceptivos, cognitivos o afectivos. La renuncia viene como consecuencia del deseo amoroso de unión con el objeto de la relación, deseado y seleccionado (el objeto mental Dios). Este objeto de relación amorosa sobrepasa el valor de todos los demás objetos de relación. Esta renuncia a los propios deseos abre la capacitad de simbolización, de una nueva y mayor creatividad mental.

La vida mística transforma. Conduce hacia un crecimiento personal. Esto se constata experimentalmente en personas que viven este proceso. Crece su propia identidad personal y se convierte en sujeto de conductas con buena relación personal con los otros, tanto en el plano social, en actividades constructivas, como en el personal de estima amorosa y activa.

El núcleo de la experiencia mística es el despojamiento interior de deseos egocéntricos para encontrar una relación de entrega al otro lo cual apunta a una relación de unión amorosa total. La persona que tiende a la experiencia mística se forma un proceso laborioso en que renuncia a otras relaciones 
porque ha deseado establecerse interiormente en la relación fundamental con Dios, un Dios que va encontrando dentro de él en un proceso de interiorización y de identificación.

(Es por el proceso de duelo, del que hemos hablado antes, por el que se recrea y se intensifica, dolorosamente, la función simbolizadora que lleva hacia la experiencia de Dios. Al despojarse de relaciones limitadas y caducas abre paso a una relación con Dios ilimitada e inefable que conduce a una vivencia de unidad con el Todo, con el misterio ${ }^{12}$ ).

\section{El camino místico es un proceso evolutivo de crecimiento en el amor humano que trasciende}

El camino místico transcurre desde los deseos infantiles egocéntricos, biológicos, pasando por el deseo y amor al otro hasta alcanzar la unión en el amor. La vida espiritual empieza en el origen de la vida humana y culmina, pero no acaba en el amor unitivo místico. ¿Cómo se puede concebir que la «carne», la corporalidad biológica se vaya transformando en espiritualidad, en amor unitivo?

En el principio, al nacer, el potencial de la vida se manifiesta buscando satisfacer las necesidades biológicas. Se busca para sobrevivir al salir del útero materno. La propia unidad del sujeto ha sido amenazada por las escisiones en el entorno que lo ha configurado. Necesita y encuentra la relación de contacto, físico, con el otro, con satisfacción.

Como hemos ya descrito antes, seguirá buscando luego hasta encontrar la unión con el otro y lo Otro en unión satisfactoria. Ha seguido un proceso, un continuum evolutivo, con potencialidad de evolución madurativa que va del placer primitivo a los afectos psíquicos, al gusto de ser amado y amar, y a la plenitud de sentirse en unidad con el objeto amado.

Se ha iniciado con el deseo de corporalidad de la «carne». Se ha buscado la unidad psicológica de amor con otro humano, la alteridad del amor. Se tiende a la unión con la Vida, con el Todo.

En la vivencia mística profunda ya no se busca satisfacción en la relación. Se encuentra el gozo de la plenitud, se vive en ella... No hay término en la vivencia de unión. Aunque permanece la corporalidad humana en otro nivel relacional limitado.

Podríamos poner ejemplos del budismo, del taoísmo... pondremos por ejemplo a San Juan de la Cruz en la Subida al Monte Carmelo señala «donde no hay camino", lo cual expresa que la realidad de Dios es una realidad no cósmica y expresa también que somos inacabados: hay una realidad no física que la estamos viviendo físicamente, la intuimos, en eso consiste la vivencia de confianza, la fe. La fe es una convicción: confiar, aunque sea sin sentimientos gratificantes, en la Realidad/Dios, y esta confianza se traduce en obras.

12 Se puede vislumbrar la correspondencia con las fases ascéticas de: vía purgativa, vía iluminativa, y vía unitiva. 
Lo que orienta finalísticamente la vida es: impulso afectivo, la intuición, la confianza en la Realidad (Dios). Los símbolos, la palabra, no pueden expresarlo todo. Se está ante una incapacidad, inefabilidad, para expresar en símbolos y palabras la vivencia mística. («Moradas», $6^{\mathrm{a}}$ y $7^{\mathrm{a}}$ ).

\section{¿Hay místicas psicopatológicas?}

Entendemos por patología, enfermedad..., no la falta de salud, sino los accidentes que surgen en el proceso vital de evolución humana y que proviene del exterior o del interior del sujeto. La religión y la espiritualidad que participan del proceso evolutivo de maduración pueden quedar afectadas por los accidentes o dificultades.

La maduración espiritual, y la mística, conlleva la maduración psicológica. Hay ejemplos de personas que logran estadios de experiencia mística y que experimentan y muestran en sus relaciones personales y conducta, una madurez excelente. Pero si el ser humano no se desarrolla en todas sus dimensiones, la dimensión espiritual puede quedar desvirtuada.

Cabe todavía la pregunta: ¿no será la experiencia mística una regresión infantil o una manifestación psicótica? Es decir, ¿no se puede ver en la experiencia mística una relación con las experiencias emocionales de fusión simbiótica como las que un niño tiene con la madre y que el místico trata de reencontrar? ${ }^{13} ¿$ No podría ser que las experiencias místicas fueran experiencias psicológicas regresivas? ${ }^{14} ¿$ No hay en la mística elementos sintomáticos de tipo psicótico como la clarividencia de ciertas convicciones?

En cuanto a la posibilidad de ser un fenómeno regresivo, hay que decir que la cuestión radica en la psicogénesis del fenómeno místico. Cuando se dice que la mística es un estado regresivo, se hace referencia a estados más o menos confusos de la relación infantil y se reviven los estados psicóticos. Ahora bien, hay una diferencia radical entre el estado psicótico, confuso, y la unión mística sana, en la que se mantiene la plena diferenciación entre Dios y la persona psicológicamente adulta dentro de un proceso amoroso de unión y fusión, no confusión («Ya no soy yo sino Cristo que vive en mi»), proceso integrador y creativo, a diferencia de los estados psicóticos, en que se da la confusión con el otro en vez de una relación de unión entre la persona y Dios.

La experiencia mística sana tiende al crecimiento emocional y personal del sujeto y no a la regresión. En el sujeto esto se manifiesta en la capacidad de desprenderse de los rasgos narcisistas y egocéntricos en favor del amor al otro: de Dios y del prójimo. Crecen las capacidades relacionales que devienen satisfactorias para el sujeto mismo y para los demás.

13 Mahler, M., «Psychoanalysis and Contemporary Science», citado en Concilium, núm. 176 (junio de 1982); Ídem, El reto de la psicología a la fe, Cristiandad, Madrid, 1975.

14 Prince, R. H., «Los estados místicos y el concepto de regresión», en WHITE, J., La experiencia mística, Kairós, Barcelona, 2005. 
Finalmente, el sentimiento de sentirse pecador en el proceso místico no se debe confundir con un sentimiento de culpa patológica.

Hay distintos tipos de culpa. La más grave, la psicótica; la obsesiva de tipo paranoide y la de tipo neurótico. Pero existe también una culpa normal, que tiende a la reparación. ¿Hay sentimiento de culpa en el místico? Leyendo textos de experiencias místicas hallamos con frecuencia el culpabilizarse,

El místico capta la distancia desproporcionada que existe entre el Dios que es amor y los límites de su propio amor. De esta desproporción puede nacer un sentimiento de dolor, de desagradecimiento para con Dios: un sentirse pecador, haber optado por su egocentrismo. El deseo de Dios y la experiencia de amor lo llena, sin embargo, de gozo, aunque sufre cuando pasa por el proceso doloroso de hacer el duelo y de reparar las carencias o las culpas propias, sanas.

En este caso la culpa deja de ser un residuo infantil de relaciones no maduras, por ejemplo, un sentimiento de culpa edípico, que juntamente con mecanismos de defensa obsesivos, Freud colocaba en la neurosis social religiosa. La culpa del místico no es una culpa neurótica. Es un indicador de madurez, de crecimiento creativo el perdón que se da a quien lo haya ofendido.

ALGUNAS PREGUNTAS: Y EL ESPÍRITU, ¿DÓNDE ESTÁ?

Con lo que acabamos de expresar al tratar del fenómeno místico no pretendemos entrar en el porqué de la acción del Espíritu, que es de un orden diferente. Sí que se intentamos, sin embargo, comprender cómo se produce psicológicamente.

Para el creyente, el Dios trascendente está en otra realidad, no física, pero la percepción psicológica que tiene de Él es una percepción real y, naturalmente, dentro de un orden físico.

La evolución madurativa lleva a intuir una realidad y aceptar los límites de la propia realidad que mantiene y refuerza la conciencia de confianza en otra realidad. La experiencia mística lleva a abrazar lo más íntimo de la existencia.

¿Qué relación hay entre la experiencia inefable y las «neuronas»?

A medida que se va buscando y alcanzando el abandono de lo egocéntrico y se va abandonando a una relación de entrega al Otro el registro de la actividad neurológica es menor. Ya no se percibe la relación con el otro unido a mí, se va perdiendo la percepción del otro y se entra en una vivencia no ya del otro sino de vivir en el otro, no se puede ya decir que es uno que vive en el otro, sino que se Es, se vive el otro, ya no hay otro ni yo (cfr. Santa Teresa, $7^{\mathrm{a}}$ Morada).

Toda experiencia espiritual tiene su correlato psíquico en el cerebro ${ }^{15}$. Pero el paso a la vivencia de la realidad de Dios ya no tiene símbolo. Es percepción

15 Pueden verse las obras de Rubia, F. J., El cerebro nos engaña, Temas de hoy, Madrid, 2000, y «La conexión divina». La experiencia mística y la neurobiología, Drakontos, Barcelona, 2003 
sin conceptos, sin símbolos. Los símbolos, la palabra, no puede expresar esos momentos. Se está ante una incapacidad inefabilidad de expresar en símbolos y palabras la vivencia mística (releer la $7^{\mathrm{a}}$ Morada de Santa Teresa de Jesús).

Resumiendo:

a) La mística es un proceso psicológico evolutivo hacia una relación con el Todo que tiende a una unión y fusión amorosa con él.

b) La experiencia mística busca alcanzar lo más íntimo de la existencia cuando tiende hacia la unidad de vida en el amor. Requiere unas disposiciones psicológicas maduras, fruto de una evolución personal, que no se dan aún en la infancia. Es una experiencia de crecimiento madurativo; no es una experiencia regresiva; bien al contrario.

c) La relación del creyente con el trascendente, (con Dios), es una relación espiritual de amor, que se desmarca de la idealización, o del miedo a la persecución del temido Dios omnipotente de la fantasía infantil. Es una experiencia que se inicia con experiencias conscientes y no conscientes, de actitudes activas y pasivas. Sobrepasa cualquier otra relación personal humana, ante la que se produce una desproporción entre las propias posibilidades de amar y el amor de Dios. El gozo que se genera da lugar a una situación de apogeo amoroso vital.

Fundación Vidal i Barraquer

Universitat Ramon Llull, Barcelona

JORDI FONT

[Artículo aprobado para publicación en diciembre de 2016] 